$621-501.22: 621-503.5$

\title{
自動制御系における非定常不規則信号に 対する非線形制御系の応答*
}

椹木義一**; 砂原善文**, 添田 喬***

\author{
A Statistical Study on the Response of Nonlinear Control \\ Systems Subjected to a Non-Stationary Random Input \\ by Yoshikazu S Awaragi, Yoshifumi Sunahara, \\ and Takashi SoEDA
}

In the previous paper, the authors described the statistical studies on the response of nonlinear control systems subjected to an ergodic stationary Gaussian random input.

This paper is devoted to the fundamental approaches to the non-stationary random time series which are considered to arise quite often for the automatic control systems in practice. Firstly, the response of nonlinear control systems subjected to a non-stationary random signal is evaluated. Secondly, for an example, a non-stationary Orenstein-Uhlenbeck process which is obtained by using the method of Fokker-Planck is treated. Detail illustrations are shown by several examples.

\section{1. 緒言}

著者らは，従来から実際にそくした見地にたって， 突変不規則入力をうける非線形制御系の非定常応答に 関する種々の統計学的研究を笑施してきた

この理論的研究において考慮した制御采の回路特性 注，卡の自力修正といら適応制御方式への応用を考兄 （1）時間に対して規則的に变動する場合，（2）時間 に対して不規則に変動する場合，とにわけ，さらに系 に印加される不規則信号，すなわち，時間的に予湘で きない目標値の変化，あるいは系の各部分に加光られ る不規則外乱に対しては定常性を仮定してきた。しか し, この仮定は解析上の便宜的処置であって, その入力 は当然非定常確率過程と久なされなければならない。

したがって，一般的視野にたってより実際的研究を おこならためには，この非定常不規則入力信号を考慮 した自動制御の理論体系を確立しなければならない。

ここではこのような研究の端緒として

（1）非定常不規則入力が非線形制御系に印加され たときの非定常応答を評価する一般的手法

（2）自動制御系に印加される非定常不規則入力の

* 昭和 38 年 4 月 2 日 第 40 期通常総会講演会に扣いて講演, 原稿受付 昭和 38 年 10 月 18 日.

** 正買, 京都大学工学部.

*** 正員, 德島大学工学部 (德島市南常三島町 2 ○ 1 ).
具体例，ならびにその統計学的表現法 について考察し, さらに, 制御系が線形である場合, 扣よび入力が定常確率過程である場合との差異につい て述べる。ただし，制御系の回路特性は，時間に対し て変化しないものとする.

\section{2. おもな記号の説明}

$$
\begin{aligned}
& t: \text { 時間 } \\
& \tau: \text { 時間 } t_{1} \text { と } t_{2} \text { との時間間隔 }
\end{aligned}
$$

$\omega, f$ : 角周波数怙よび振動数

$s:$ ラプラス演算子

$v(t):$ 制御系の目標值信号

$u(t) ：$ 正規性不規則外乱

$x(t)$ : 制御量

$z(t)$, 扣よび $y(t)$ : 非線形要素に対する 入, 出力 信号

$f[z(t)]$ ： Zero-memory 形非線形伝澾特性

$A_{i}, k, T:$ 制御系の回路特性値

$R_{w}\left(t_{1} ; \tau\right)$ ：時間 $t_{1}$ 拉よび時間間隔 $\tau$ に依存する $u(t)$ の自己相関関数

$S_{u}\left(t_{1} ; f\right)$ : 時間 $t_{1}$ 飞依存する $u(t)$ のスペクトル 密度

$\phi_{z}(t)$ ：時間 $t$ に抢ける応答 $z(t)$ の二乗平均值 $<\cdot>_{\mathrm{av}}$ : : 記号. の集合平均値 


\section{3. 応答 $z(t)$ の二乗平均値の評価}

第1四に示したように，原点に関して対称な，Zeromemory 形非線形要素を含む制御系を考察する。ただ ᄂ, 入力 $z(t)$ と出力 $y(t)$ との関係は $y(t)=f[z(t)]$ によって与えられるるのとする。また， $G_{2}(s)$ は線形 要萃の伝達関数であり

$$
G_{2}(s)=k / \sum_{i=0}^{N} A_{i} s^{i} \quad\left(A_{i} \tilde{k}: \text { 正の定数 }\right)
$$

によってあらわされるるのとする。

目䅺値信号 $v(t)=0$ とし, 非定常不規則外乱 $u(t)$ (平均值は零とする)が，このような系に印加されたと きの非定常応答 $z(t)$ を，その二乗平均值 $\phi_{z}(t)$ に注 目乙て評価する手法について述べる。

$u(t)$ と $z(t)$ との関係を示す制御方程式をつくれば

$$
\sum_{i=0}^{N} A_{i} d^{i} z(t) / d t^{i}+k f[z(t)]=k u(t)
$$

となる。解析を容易ならしめるため，すでに著者らが

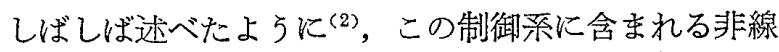
形要素を，それと等価なゲイン 置換すれば（2 )式は

$$
\sum_{i=0}^{N} A_{i} d^{i} z(t) / d t^{i}+k \kappa z(t)=k u(t)
$$

そなる.ここに， $\kappa$ は $z(t)$ の二乗平均值 $\phi_{z}(t)$ の関 数えして

$$
\kappa\left[\psi_{z}(t)\right]=\int_{-\infty}^{\infty} z f(z) p(z, t) d z / \int_{-\infty}^{\infty} z^{2} p(z, t) d z
$$

のよ5に与えられ，また $p(z, t)$ は時間 $t$ に和ける応
答 $z(t)$ の正規性確率密度関数;

$$
p(z, t)=\frac{1}{\sqrt{2 \pi \psi_{z}(t)}} \exp \left\{-\frac{z^{2}}{2 \psi_{z}(t)}\right\}
$$

である。

さて，等価線形化制御方程式 ( 3 )式から得られる荷 重関数 $W\left(t_{n}, \tau_{1}\right)$ (時間 $\tau_{1}$ において単位インパルス を印加したときの，時間 $t_{n}$ に和ける㐫答）は，未知 係数 $\kappa$ の関数として定まるから, その応答は, 非定 常不規則入力の印加される時間 $t_{0}$ の值, ならびに非 線形伝達特性の形状（したがって等価ゲインの值）に よってつぎのように分けて解析する*.

$3 \cdot 1 \boldsymbol{t}_{0}=$ 有限の場合 第2図（a）に示したよう に, 外乱 $u(t)$ が時間 $t=t_{0}$ で突発的に柔に印加され る場合であり，さらにこれを，つぎの三つの場合にわ ける.

（a）初期値 $\kappa_{0}=\kappa\left[\phi_{z}\left(t_{0}\right)\right]$ が有限確定值をとる場 合このとき， $t=t_{n}$ に拉ける応答 $z\left(t_{n}\right)$ は

$$
z\left(t_{n}\right)=\int_{t_{0}}^{t_{n}} W\left(t_{n}, \tau_{1}\right) u\left(\tau_{1}\right) d \tau_{1}
$$

となる。経過時間 $t$ を $t_{j+1}-t_{j}=\Delta_{j}[j=0,1,2, \cdots$,

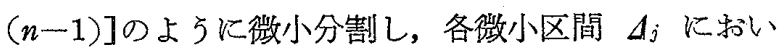
ては等価ゲイン $\kappa$ の值は一定值 $\kappa_{j}$ をるるのとす れば,（6)式は

$$
z\left(t_{n}\right)=\sum_{j=0}^{n-1} \int_{t_{j}}^{t_{j+1}} W\left(t_{n}-\tau_{1}\right) \mid u\left(\tau_{1}\right) d \tau_{1}
$$

のようにあらわされる、したがって， $z\left(t_{n}\right)$ の二乗平 均值 $\psi_{z}\left(t_{n}\right)$ は

$$
\phi_{z}\left(t_{n}\right) \equiv<z\left(t_{n}\right)^{2}>\mathrm{av} .=\sum_{i}^{n-1} \int_{t_{j}}^{t_{j+1}} \int_{t_{i}}^{t_{i+1}} W\left(t_{n}-\tau_{1}\right)\left|\underset{\kappa=\kappa_{j}}{W\left(t_{n}-\tau_{2}\right) \mid}\right|_{\kappa=\kappa_{i}}\left\langle u\left(\tau_{1}\right) u\left(\tau_{2}\right)>\text { av. } d \tau_{1} d \tau_{2}\right.
$$

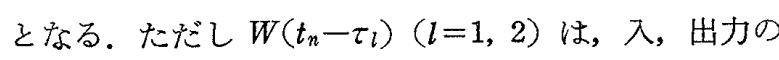
関係が (2）式で与えられた系の， $\kappa$ を一定としたと きの荷重関数である。また， $\kappa_{m}(m=i, j)$ 性制御系に 含まれる非線形要素の形状方゙定まれば，(4)式から

$$
\kappa_{m}=\kappa\left[\psi_{z}\left(t_{m}\right)\right] \quad(m=i, j) \cdots
$$

のように与えられる。

また， $<u\left(\tau_{1}\right) u\left(\tau_{2}\right)>$ av. は, $u(t)$ の時間 $t_{1}$ 和よ び $t_{2}$ に和ける $u(t)$ の非定常自己相関関数であり， 一般に $\tau_{1}-\tau_{2}=\tau>0$ と捇けば

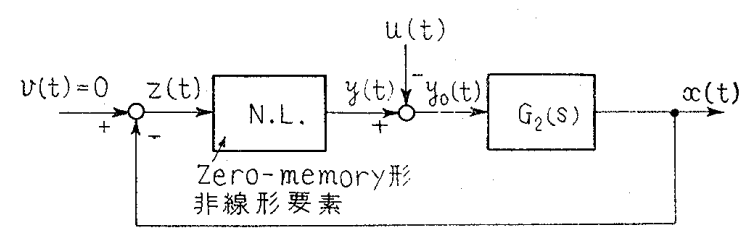

第 1 図 非定常不規則入力信号をらける 非線形制御系のブロック線図

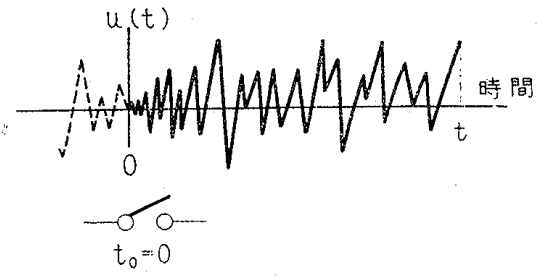

(a) 突变非定常不規則信男

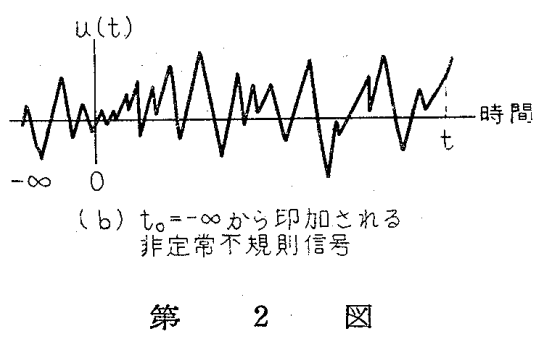

* 線形制御系の場合は，荷雷関数に舍まれる係数はすべて既知であ るから，その応答を評洒するにあたっては，てのように分類する 必要恃ない(3)。 


$$
\begin{aligned}
\left\langle u\left(\tau_{1}\right) u\left(\tau_{2}\right)>_{\mathrm{av} .}\right. & =\left\langle u\left(\tau_{1}\right) u\left(\tau_{1}-\tau\right)>_{\mathrm{av} .}=R_{u}\left(\tau_{1} ; \tau\right)\right. \\
& =\left\langle u\left(\tau_{2}\right) u\left(\tau_{1}\right)>_{\mathrm{av} .}=\left\langle u\left(\tau_{2}\right) u\left(\tau_{2}+\tau\right)>_{\mathrm{av} .}=R_{u}\left(\tau_{2} ;-\tau\right)\right.\right.
\end{aligned}
$$

となる，したがって，積分变換公式（第 3 図および付録 $\mathrm{A}$ 参照）

$$
\int_{t_{i}}^{t_{i+1}} \int_{t_{j}}^{t_{j+1}} d \tau_{1} d \tau_{2}=\int_{t_{i}}^{t_{i+1}} d \tau_{1} \int_{t_{i+1}-t_{j+1}}^{\tau_{1}-t_{j}} d \tau+\int_{t_{j}}^{t_{j+1}} d \tau_{2} \int_{t_{i-1} \tau_{2}}^{t_{i+1}-t_{j+1}} d \tau
$$

就よび(10)式を(8)式へ適用すれば，すでに示した手法により(2) 初期值 $\kappa_{0}=\kappa\left[\psi_{z}\left(t_{0}\right)\right]$ から, 逐次 $\psi_{z}\left(t_{n}\right)$ を評 価することができる。

また，時間分割区間 $A_{j}$ にくらべ，等価ゲイン $\kappa_{j+1}$ と $\kappa_{j}$ との变化量が微小であるときは，(8)式のかる りに

$$
\psi_{z}\left(t_{n}\right)=\left.\int_{t_{0}}^{t_{n}} \int_{t_{0}}^{t_{n}} W\left(t_{n}-\tau_{1}\right) W\left(t_{n}-\tau_{2}\right)\right|_{\kappa=\kappa_{n-1}}<u\left(\tau_{1}\right) u\left(\tau_{2}\right)>\text { av. } d \tau_{1} d \tau_{2}
$$

ただし

$$
\kappa_{n-1}=\kappa\left[\phi_{z}\left(t_{n_{-1}}\right)\right]
$$

を用いればよい。

このようにして，初期条件が定まり，さらに，非定常不規則入力信号 $u(t)$ の自己相関関数が，時間間隔 $\tau$ 拉 よび $\tau_{1}$ (または $\tau_{2}$ ）の関数として表現できるときは，(8)式および(9)式，あるいは(12)式を用いて，非定常 応答 $\phi_{z}(t)$ を評価することがでさる。

（b）初期值 $\kappa_{0}=\kappa\left[\phi_{z}\left(t_{0}\right)\right]$ が有限確定值をとらない場合 制御系に含まれる非線形要素の伝達特性の形状 によっては，初期值 $\kappa_{0}=\kappa\left[\psi_{z}\left(t_{0}\right)\right]$ が定まらない場合がある。このときは，以下にのべる近似解法を適用する。

$3 \cdot 2 \quad \boldsymbol{t}_{0}=-\infty$ の場合 [第 2 図 $(\mathrm{b})$ 参照] このとき, 応答 $z\left(t_{n}\right)$ は

$$
z\left(t_{n}\right)=\int_{-\infty}^{t_{n}} W\left(t_{n}, \tau_{1}\right) u\left(\tau_{1}\right) d \tau_{1}
$$

となり，その非定裳応答 $\psi_{z}\left(t_{n}\right)$ は

$$
\psi_{z}\left(t_{n}\right) \equiv<z\left(t_{n}\right)^{2}>\mathrm{av} .=\int_{-\infty}^{t_{n}} \int_{-\infty}^{t_{n}} W\left(t_{n}, \tau_{1}\right) W\left(t_{n}, \tau_{2}\right)<u\left(\tau_{1}\right) u\left(\tau_{2}\right)>\mathrm{av} . d \tau_{1} d \tau_{2} \ldots
$$

によって与えられる*. 矛に定位性があるものとして, (a)で用いた初期条件に対する条件を定める。すなわち，

(i) 定常值 $\operatorname{lin}_{t_{n \rightarrow \infty}} \phi_{z}\left(t_{n}\right) \equiv \phi_{z}$, および定常等洒ゲイン $\kappa_{s}$ の值を計算する(1)

(ii) (i)で求めたゲイン $\kappa_{\text {。 }}$ を用いて

$$
\phi_{z}\left(t_{s}\right)=\int_{-\infty}^{t_{s}} \int_{-\infty}^{t_{s}} W\left(t_{n}-\tau_{1}\right) W\left(t_{n}-\tau_{2}\right) \mid<u\left(\tau_{1}\right) u\left(\tau_{2}\right)>\operatorname{av} . d \tau_{1} d \tau_{2}
$$

を計算し，この值が汪とんど定常值 $\phi_{z}$ と等しいとみ度される時間 $t=t_{s}$ を求める。

(iii) 最終条件を

$$
t=t_{s} \text { に抏いて } \kappa=\kappa_{s}
$$

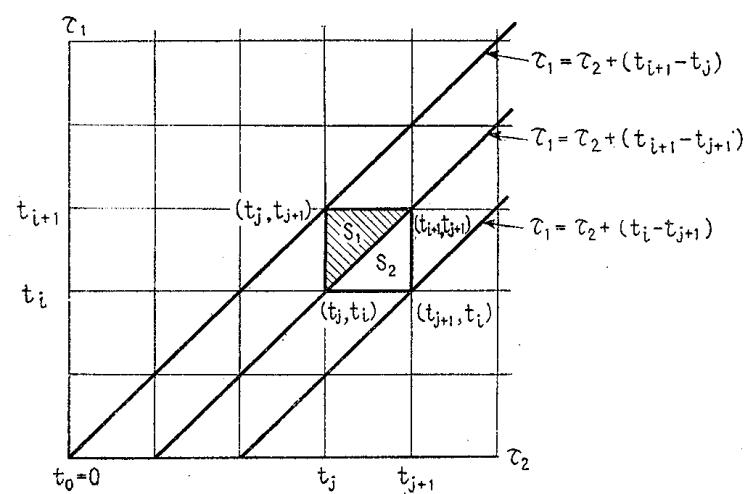

第 3 困積分領域の変更（分割注等間隔）
と定める.

(iv) $t=t_{s}$ より時間 $t$ を $t_{s_{-j+1}}-t_{s_{-j}}=\Delta_{s_{-j}}(j=$ $1,2,3, \cdots)$ のように時間の経過に逆行して微小分割 する.

このとき各時点 $t_{s_{-} j}$ に括ける応答は

$$
\begin{aligned}
& \phi_{z}\left(t_{s-j}\right)=\int_{-\infty}^{t_{s-j}} \int_{-\infty}^{t_{s-j}} W\left(t_{s-j}-\tau_{1}\right) \\
& \left.W\left(t_{s-j}-\tau_{2}\right)\right|_{\kappa=\kappa_{s-j+1}} ^{<}<\left(\tau_{1}\right) u\left(\tau_{2}\right)>a \nabla . d \tau_{1} d \tau_{2}
\end{aligned}
$$

\footnotetext{
*ここでは, 回路特性は定数と考えているから，入力が定常信号の嚗合，その応答は定常確率過程となり，非定常性はあらわれない(3).
} 
および

$$
\kappa_{s-j+1}=\kappa\left[\psi_{z}\left(t_{s-j+1}\right)\right] \quad(j=1,2,3, \cdots)
$$

を用いて評価することができる。したがって，初期值 $\kappa_{0}$ が有限確定値をとらない場合まをたは， $t_{0}=-\infty の$ 場合は，(17)，(18)式扔上び变换公式

$$
\int_{-\infty}^{t_{s-j}} \int_{-\infty}^{t_{s-j}} d \tau_{1} d \tau_{2}=\int_{-\infty}^{t_{s-j}} d \tau_{1} \int_{0}^{\infty} d \tau+\int_{-\infty}^{t_{s-j}} d \tau_{2} \int_{-\infty}^{0} d \tau
$$

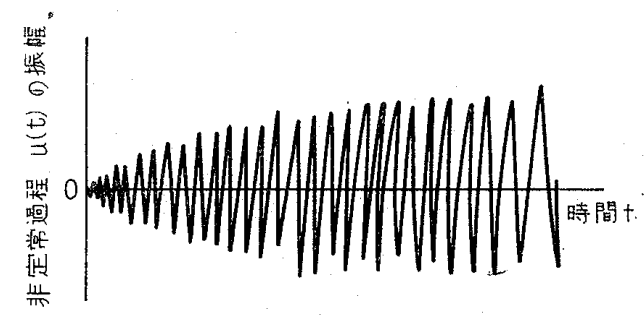

第 4 図 非定常 O.U. 過程の一例

を用いて，最終値条件(16)式から逐次その応答を評価すればよい。

\section{4. 具 体 例}

実在の自動制御系に印加される非定常不規則入力信号としては種ふ侾えられるが，ここでは最も基本的な，第 4 図に示したような信号について考察をする（具体的には，飛しょう体や建物に吹きつける風の上5に，時間の 経過とともに徐々にその強さを增し，ついは定常状態へと移行する不規則外乱が考えられる)，このような信 号は統計学的にどのように表現され，乙かもこのときの非定常応答は，系の性質によりどのように变化するかを 以下に述べる.

$4 \cdot 1$ 非定常不規則入カ いままでの統計学的研究に扔いてしばしば用いてきた定常不規則入力は，その自己 相関関数が

$$
R_{x}(\tau)=D \exp (-\beta|\tau|) \quad(D, \beta: \text { 正の定数 })
$$

によってあらわされる O.U. 過程であった。したがって，ここで取扱う非定常確率過程は，定常状態では（20） 式の上万統計学的性質をるつものとする。一般の不規則信号が O. U. 過程に属するとき，その確率密度関数 は,フォッカー・プランク (Fokker-Planck) 方程式

$$
\left\{L^{*}-\frac{\partial}{\partial t}\right\} p_{1}\left(u, t ; u_{0}, t_{0}\right)=0
$$

ただし

$$
L^{*}=\frac{1}{2} \frac{\partial^{2}}{\partial u}+\frac{1}{\sigma} u \frac{\partial}{\partial u}+\frac{1}{\sigma} \quad(\sigma: \text { 正の定数 })
$$

を満足するから (4), いま初期条件は $t_{0}=0, u_{0}=0$ であるとすれば, (21)式の解は

$$
p_{1}(u, t)=\frac{1}{\sqrt{2 \pi\left\{\sigma\left(1-e^{-2 t / \sigma}\right) / 2\right\}}} \exp \left\{-\frac{u^{2}}{\sigma\left(1-e^{-2 t / \sigma}\right) / 2}\right\}
$$

となる。ただし（21）式の $p_{1}\left(u, t ; u_{0}, t_{0}\right)$ は，時間 $t=t_{0}$ に和いて $u\left(t_{0}\right)=u_{0}$ であるとき，時間 $t$ において $u<u(t)<u+d u$ をとる確率が $p_{1}\left(u, t ; u_{0}, t_{0}\right) d u$ である 推移確率密度関数である。 したがって,$u(t)$ の二乗平 均值 $\psi_{u}(t)$ の時間にとるなら变動の模様は (23)式から

$$
\psi_{u}(t)=\frac{\sigma}{2}\{1-\exp (-2 t / \sigma)\}
$$

であることがわかる。一方すすで述べたように，定常状態では（20）式のような自己相関関数をるつから，こ こで考察している非定常不規則信号 $u(t)$ のそれは, 次式のような形で表現されるとみなしてよい。

$$
R_{u}(t ; \tau)=\frac{\sigma_{1}}{2} \exp (-\beta|\tau|)\{1-\exp (-2 t / \sigma)\} \quad\left(\sigma_{1} \text { : 定数 }\right)
$$

このとき，(25)式に対応する非定常スペクトル密度を計算すれば

$$
\begin{aligned}
S_{u}(t, f)= & \sigma_{1}\{1-\exp (-2 t / \sigma)\}\left[\frac{2 \beta}{\beta^{2}+(2 \pi f)^{2}}+\frac{2}{\beta^{2}+(2 \pi f)^{2}} \exp (-\beta t)\right. \\
& \left.\times\left(2 \pi f \sin 2 \pi f t_{1}-\beta \cos 2 \pi f t_{1}\right)\right]
\end{aligned}
$$

となる (付録 $\mathrm{B}$ 参照)，第 5 図は，時間の経過にとるならスペクトル密度の変化の模様，すなわち(26)式を示し たものである. 
$4 \cdot 2$ 非定常応答 例-1 考察する制御系の制御方程式は, (2)式に执いて, $N=1, A_{0}=1, A_{1}=T$ (時 定数) そする. この制御系へ，自己相関関数が(25)式で与光られるような外乱 $u(t)$ が時間 $t=0$ に招いて笑発 的汇印加されたときの $\phi_{z}(t)$ を，(12)式を用いて評価してみる。

(3)式に対応与る等価線形化制御方程式は,

$$
T d z(t) / d t+z(t)+k_{\kappa} z(t)=k u(t)
$$

となるから，この樂の荷重関数を，を一定として計算すれば

$$
W\left(t-\tau_{1}\right)=\frac{k}{T} \exp \left\{-\frac{1+k \kappa}{T}\left(t-\tau_{1}\right)\right\} \quad\left(t>\tau_{1}\right)
$$

となる。したがって(25)式和よび(28)式を(12)式へ適用して $\psi_{z}\left(t_{n}\right)$ を計算すれば次式のようになる。

$$
\begin{aligned}
\frac{\psi_{2}\left(t_{n}\right)}{\sigma_{1}}= & k^{2}\left[\frac{1}{\left(1+k_{\kappa}\right)\left(1+k_{\kappa}+\beta T\right)}+\frac{4 T / \sigma}{\left(1+k_{\kappa}-\beta T\right)\left(1+k_{\kappa}+\beta T\right)\left(1+k_{\kappa}+\beta T-2 T / \sigma\right)}\right. \\
& \times \exp \left\{-\left(\beta+\frac{1+k_{\kappa}}{T}\right) t\right\}-\frac{T / \sigma}{\left(1+k_{\kappa}\right)\left(1+k_{\kappa}-\beta T\right)\left(1+k_{\kappa}-T / \sigma\right)} \\
& \left.\times \exp \left(-2 \frac{1+k_{\kappa}}{T} t\right)-\frac{T / \sigma}{\left(1+k_{\kappa}-T / \sigma\right)\left(1+k_{\kappa}+\beta T-2 T / \sigma\right)} \exp (-2 t / \sigma)\right] \mid
\end{aligned}
$$

いま，非線形要素の伝達特性が

$$
(z)= \begin{cases}-a & (z<-a) \\ z & (|z|<a) \\ a & (z>a)\end{cases}
$$

によって与えられたときの応答を評価する。このと き，(30)式に対応する等価ダイン $\kappa$ の值は

$$
\kappa=2 \Phi\left\{a / \sqrt{\phi_{z}(t)}\right\}
$$

となる。ただし

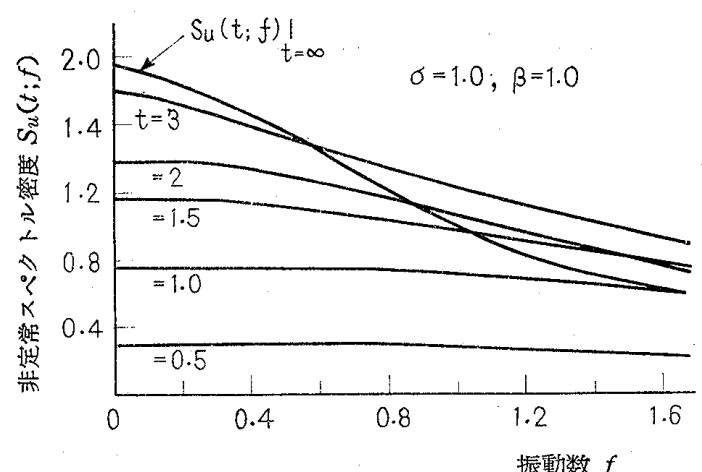

第 5 図 時間 $t$ 亿依存する非定常スペクトル 密度の一例

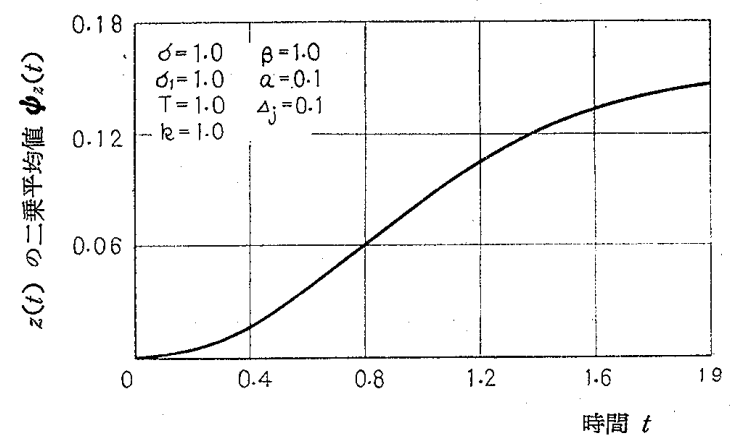

第 6 図 具体例 1 飞示した制御系の非定常応答

$$
\Phi(\zeta)=\frac{1}{\sqrt{2 \pi}} \int_{0}^{\zeta} \exp \left(-\frac{\theta^{2}}{2}\right) d \theta
$$

である、したがって， $\phi_{z}\left(t_{n}\right)$ は， $\kappa_{0}=1$ であることを 考慮することによって(29)式执よび(31)式より逐次評 価される。第 6 図は，T=1.0, $k=1.0, \beta=1.0, a=$ $1.0, \sigma=\sigma_{1}=1.0$ 特よび $\Delta_{j}=0.1$ としたときの $\phi_{z}(t)$ の計算結果を示したものである.

例-2 第7四に示したブロック線図によってあら わされる制御系を考察する。ただし，制御対象に含季 れる線形要素の伝達関数は

$$
G_{2}(s)=k /(1+T s)
$$

とする. いま, 目標值信号 $v(t)$ の自己相関関数が (25)式によって与兄られたときの $\psi_{z}(t)$ を評価する.

このとき, $v(t)$ と $z(t)$ との関係を示す等価線形化 制御方程式は

$$
T d z(t) / d t+z(t)+k_{\kappa} z(t)=T d v(t) / d t+v(t) \cdots(34)
$$

となるから，кを一定としたときの荷重関数は

$$
\begin{aligned}
& W\left(t-\tau_{1}\right)=\delta\left(t-\tau_{1}\right) \\
& \quad+\frac{1+k \kappa}{T} \exp \left\{-\frac{1+k \kappa}{T}\left(t-\tau_{1}\right)\right\} \quad\left(t>\tau_{1}\right)
\end{aligned}
$$

によって与えられる。ただし $\delta$ は Dirac のデルタ関 数である. 前例々同様にして $\phi_{z}\left(t_{n}\right)$ を求めれば次式 のようになる。

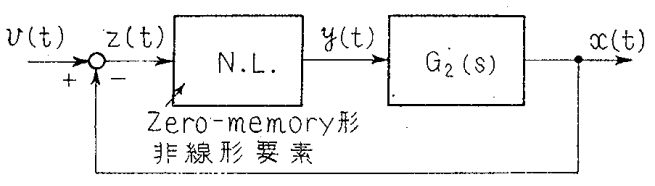

第 7 因 具体例 2 に示した非線形制御系 のブロック線因 
30 巻 215 号 (昭 $39-7$ )

$$
\begin{aligned}
\frac{\varphi_{z}\left(t_{n}\right)}{\sigma_{1}}= & \frac{1+\beta T\left(1+k_{\kappa}\right)}{\left(1+k_{\kappa}\right)\left(1+k_{\kappa}+\beta T\right)}+\frac{4\left(k_{\kappa}\right)^{2} T / \sigma}{\left(1+k_{\kappa}+\beta T\right)\left(1+k_{\kappa}-\beta T\right)\left(1+k_{\kappa}+\beta T-2 T / \sigma\right)} \\
& \left.\times \exp \left\{-\beta+\frac{1+k_{\kappa}}{T}\right) t\right\}+\frac{2 k_{\kappa}}{\left(1+k_{\kappa}+\beta T\right)}\{1-\exp (-2 t / \sigma)\} \\
& \times \exp \left\{-\left(\beta+\frac{1+k_{\kappa}}{T}\right) t\right\}+\left(k_{\kappa}\right)^{2}\left\{\frac{2}{\left(1+k_{\kappa}-\beta T\right)\left(1+k_{\kappa}+\beta T-2 T / \sigma\right)}\right. \\
& \left.\times \exp \left(-2 \frac{1+k_{\kappa}}{T} t\right)-\frac{\left(1-k_{\kappa}+\beta T\right)}{\left(1+k_{\kappa}+\beta T\right)} \exp (-2 t / \sigma)\right\}\left.\right|_{\substack{\kappa=k_{n-1} \\
t=t_{n}}} \ldots \ldots \ldots \ldots \ldots \ldots \ldots \ldots \ldots \ldots \ldots \ldots \ldots \ldots
\end{aligned}
$$

ただしこの式に含まれる $\sigma_{1}$ は $v(t)$ の定常分散である.非線形要素の伝達特性が $(30)$ 式によって与えられ たときの非定常応答を， $T=1.0, k=1.0, \beta=1.0, \sigma=\sigma_{1}=1.0, a=1.0$ 叔よび $\Delta_{j}=0.1$ とし，例 -1 と同 様な操作によって計算すれば，第 8 図のようになる。

\section{5. 綰言}

ここでは，末ず，非定常不規則入力が非線形制御系に，外乱または目標值信号として印加されたときの非定賞 㐫答を評価し，つぎに，最も帮際にそくした O.U. 過程に属する非定常不規則信号の統計学的性質を究明し た。この手法を滴用するにあたっては，（i ） 不規則入力信号の自己相関関数が，㬰験的，末たは経験的に(10) 式のように $\tau_{1}$ (または $\tau_{2}$ ) とての関数で定まること（ii）非線形要素の形状，执よび系に印加される入力の 状態に依存する初期条件（または最終条件）が有限確定值をとること，が必要である。

さらに，具体的な非定常不規則入力信号としては，白色雑音のようなもの（定常白色雑音か， Time-variant gain を通過したときに生ずる信号）が考えられるが，これは自己相関関数に Dirac のデルタ関数を適用する ことによって同様に議論することができる(5).

このような非定常不規則入力を考慮した制御策応答の解析を，設計計画へ適用することにより，われわれは棸 に印加される外乱や騒音の影響を最小限にぶせぐ対策をこうずることができるのである。この設計計画に関する 指針については稿を改める。

\section{付 録 $\mathbf{A}$}

積分変換公式 (11) 式の計算

$$
\begin{aligned}
t_{0}=0, t_{j+1}-t_{j}=A_{j}=\Delta & \text { (等間隔) とす。第 } 3 \text { 図より } \\
\int_{t_{i}}^{t_{i+1}} \int_{t_{j}}^{t_{j+1}} d \tau_{1} d \tau_{2} & =\int_{s 1} \int d \tau_{1} d \tau_{2}+\int_{s 2} \int d \tau_{1} d \tau_{2} \ldots \ldots \ldots \ldots \ldots \ldots \ldots \ldots \ldots \ldots \ldots \ldots \ldots \ldots \ldots \ldots \ldots \ldots \ldots \ldots \ldots \ldots \ldots \\
& =\int_{t_{i}}^{t_{i+1}} d \tau_{1} \int_{t_{j}}^{\tau_{1}-\left(t_{i+1}-t_{j+1}\right)} d \tau_{2}+\int_{t_{j}}^{t_{j+1}} d \tau_{2} \int_{t_{i}}^{\tau_{2+}}
\end{aligned}
$$

という結果をうる， $\tau_{1}-\tau_{2}=\tau$ と置換し，積分領域を変更すれば，次式のようになる。

$$
\int_{t_{i}}^{t_{i+1}} \int_{t_{j}}^{t_{j+1}} d \tau_{1} d \tau_{2}=\int_{t_{i}}^{t_{i+1}} d \tau_{1} \int_{t_{i+1}-t_{j+1}}^{\tau_{1}-t_{j}} d \tau+\int_{t_{j}}^{t_{j+1}} d \tau_{2} \int_{t_{i}-\tau_{2}}^{t_{i+1}-t_{j+1}} d \tau
$$

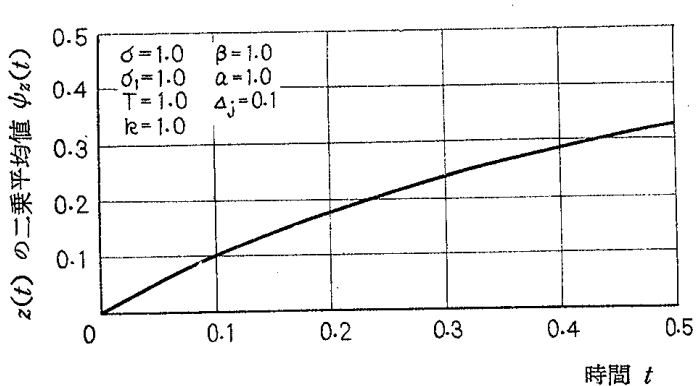

第 8 図 具体例 2 飞示した制御系の非定常応答
また（39)式から（第9図参照）

$$
\int_{0}^{t_{n}} \int_{0}^{t_{n}} d \tau_{1} d \tau_{2}=\int_{0}^{t_{n}} d \tau \int_{0}^{t_{n}-\tau} d \tau_{1}+\int_{-t_{n}}^{0} d \tau \int_{0}^{t_{n}+\tau} d \tau_{2}
$$

特よび

$$
\int_{-\infty}^{t_{n}} \int_{-\infty}^{t_{n}} d \tau_{1} d \tau_{2}=\int_{-\infty}^{t_{n}} d \tau_{1} \int_{0}^{\infty} d \tau+\int_{-\infty}^{t_{n}} d \tau_{2} \int_{-\infty}^{0} d \tau
$$

を導くことができる。 


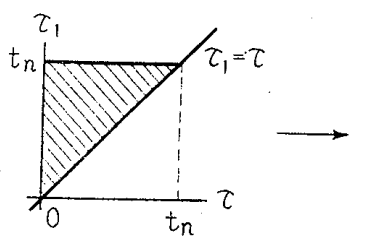

$\tau ; 0 \sim \tau_{1}$
$\tau_{1} ; 0 \sim t_{n}$

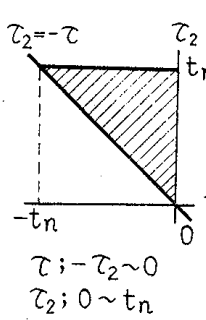

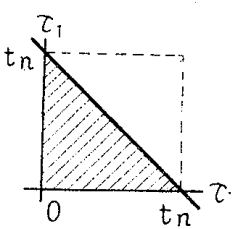

$\tau_{1} ; 0 \sim t_{n}-\tau$ $\tau ; 0 \sim t_{n}$

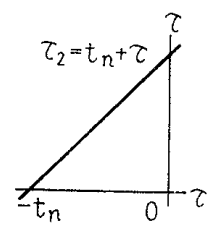

$\tau_{2} ; 0 \sim t_{n}+\tau$ $\tau ;-t_{n} \sim 0$

\section{付 録 B}

非定常スペクトル密度, および非定常自己相関関数の計算 （a） $u\left(t^{\prime}\right)$ の定義域が $-\infty<t^{\prime}<t$ である場合 $〔 t^{\prime}>t$ で は $u\left(t^{\prime}\right)=0$ ]

$u\left(t^{\prime}\right)$ のフーリエ変換 $S_{u}(t ; f)$ は

$$
S_{u}(t ; f)=\int_{-\infty}^{t} u\left(t^{\prime}\right) e^{-j 2 \pi f t^{\prime}} d t^{\prime}
$$

によって与えられる.（42）式の共役関数形を $S_{u}^{*}(t ; f)$ とす れば

$$
S_{u} *(t ; f)=\int_{-\infty}^{t} u\left(t_{1}{ }^{\prime}\right) e^{j 2 \pi f t_{1}{ }^{\prime}} d t_{1}{ }^{\prime}
$$

となる.したがって, $u\left(t^{\prime}\right)$ の振動数 $f$ に対する Joint energy ${ }^{(6)}$ は

$$
<E(t ; f)>\text { av. }=\int_{-\infty}^{t} \int_{-\infty}^{t}<u\left(t^{\prime}\right) u\left(t_{1}^{\prime}\right)>\text { av. } e^{j 2 \pi f\left(t_{1}^{\prime}-t^{\prime}\right)} d t^{\prime} d t_{1}^{\prime}
$$

によって計算される、いま， $t_{1}{ }^{\prime}-t^{\prime}=\tau$ と置換し，(44)式に積分变換公式(41)式，拉よび(10)式の関係を用いれば

$$
<E(t ; f)>_{\mathrm{av} .}=\int_{-\infty}^{t} \int_{0}^{\infty} R_{u}\left(t_{1}{ }^{\prime}-\tau ;-\tau\right) e^{j 2 \pi f \tau} d t_{1}{ }^{\prime} d \tau+\int_{-\infty}^{\iota} \int_{0}^{\infty} R_{u}\left(t_{1}{ }^{\prime} ; \tau\right) e^{-j 2 \pi f \tau} d t_{1}{ }^{\prime} d \tau
$$

という結果をうる。 ふたたび $R_{u}\left(t_{1}{ }^{\prime} ; \tau\right)=R_{u}\left(t_{1}{ }^{\prime}-\tau ;-\tau\right)$ という関係を用いて上式を簡単にすれば

$$
<E(t ; f)>\mathrm{av} .=2 \int_{-\infty}^{t} \int_{0}^{\infty} R_{u}\left(t_{1}{ }^{\prime} ; \tau\right) \cos 2 \pi f \tau d t_{1}{ }^{\prime} d \tau
$$

となる、したがって, 時間 $t$ に偖存するスペクトル密度(6)は

$$
S_{u}(t ; f)=2 \frac{\partial}{\partial t}[<E(t ; f)>\text { av. }]
$$

によって計算され，その結果は

$$
S_{u}(t ; f)=4 \int_{0}^{\infty} R_{u}(t ; \tau) \cos 2 \pi f \tau d \tau
$$

となる、このとき，自己相関関 $R_{u}(t ; \rho)$ は次式によって与えられることがわかる。

$$
R_{u}(t ; \rho)=\int_{0}^{\infty} S_{u}(t ; f) \cos 2 \pi f \rho d f
$$

（b） $u\left(t^{\prime}\right)$ の定義域が $0<t^{\prime}<t$ である場合 $\left[t^{\prime}>t\right.$ では $\left.u\left(t^{\prime}\right)=0\right]$

このときは（48)式に対応するスペクトル泌度の式 は

$$
S_{u}(t ; f)=4 \int_{0}^{t} R_{u}(t ; \tau) \cos 2 \pi f d \tau
$$

となり, 自己相関関数の形状は(49)式のようになるこ とを，(a)の場合と同様にして導くことができる。

\section{文献}

(1) Y. Sawaragi \& others, Statistical Studies on Non-Linear Control Systems, (1962), Nippon Print. and Pub.

(2) Y. Sawaragi \& others, Tech. Reps. Engng. Res. Inst., Kyoto Univ., 12-1, Report No.91, (1962), 1.

(3) J.H. Laning \& R.H. Battin, Random Processes in Automatic Control, (1956), McGraw-Hill.

(4) P. Deutch, Nonlinear Transformations of Random Processes, (1962), 118, Prentice-Hall, Inc.

(5) Y.K. Lin, Trans. ASME., Ser.E, 30-4 (1963), 555

(6) D.G. Lampard, J. Appl. Phys., 25-9 (1954), 855. 